\title{
Electrochemical Evaluation of Choline Oxidase on Modified Bamboo-Like CNTs Electrode: from Nano- Chemistry Towards Biotechnological Application
}

\author{
Farzaneh Golfeshan ${ }^{1}$, Allahyar Noori ${ }^{2}$, Ali Karami ${ }^{3}$, Aref Barkhordari ${ }^{4, *}$ (D), Lila Kiani ${ }^{5}$, Reza Sayyad \\ Soufdoost $^{6}$, Haidar Taimouri Raad ${ }^{5}$, Davood Zolfaghari ${ }^{5}$, Hamid Tebyanian ${ }^{3, * \text { (D) }}$
}

1 Orthodontic Research Center, School of Dentistry, Shiraz University of Medical Sciences, Shiraz, Iran

2 Exercise Physiology Research Center, Life Style Institute, Baqiyatallah University of Medical Science, Tehran, Iran

3 Research Center for Prevention of Oral and Dental Diseases, Baqiyatallah University of Medical Sciences, Tehran, Iran

4 Division of Toxicology, Department of Comparative Biosciences, Faculty of Veterinary Medicine, University of Tehran, Tehran, Iran

5 Applied Biotechnology Research Center, Baqiyatallah University of Medical Sciences, Tehran, Iran

6 Dentistry Research Institute, School of Dentistry, Shahed University, Tehran, Iran

* Correspondence: barkhordary.aref@gmail.com; tebyan.hamid@yahoo.com (H.T.)

Scopus Author ID 57205444157 (A.B.); 55220019400 (H.T.)

Received: 23.04.2020; Revised: 7.05.2020; Accepted: 7.05.2020; Published: 12.05.2020

\begin{abstract}
Carbon nanotube (CNT) can be considered as one of the best materials for enzyme nanobiosensor. In this study, we investigated comprehensively electron transfer properties in three kinds of carbon nanotubes for finding the best supporting material for comprising of the electrochemistry and electrocatalysis of enzymes in nano-dimension. Choline oxidase was selected as a sample enzyme for evaluating the performance of the electrodes. The enzyme was absorbed on modified SWCNT, MWCNT and Bamboo-like CNTs electrode in ionic liquid. Electron transfer and electroanalytical responses were investigated by Metrohm Autolab. Functionalization was studied by Raman spectroscopy and FTIR and also, the morphological evaluation was conducted by SEM. Raman spectroscopy showed that Bamboo-like CNTs had better properties in loading enzyme and other electrochemical properties for electron transfer. FTIR spectroscopy showed that Bamboo-like CNTs had high covalent binding on the surface wall of nanotubes. High loading of the enzyme was detected in Bamboo-like CNTs in comparison to two other nano-tubes by SEM. The electrochemical and amperometric response showed that Bamboo-like CNTs had a better response in different scan rates, wide linear range and detection limit. ChOx/RTIL/Bamboo-like CNTs/GC electrodes showed the high amounts of enzyme loading, high enzyme-substrate affinity, low detection limit, best sensitivity and wider linear range.
\end{abstract}

Keywords: Bamboo-like CNTs; Choline oxidase; Electron transfer; Ionic liquids; CNTs; Nanobiosensor.

(C) 2020 by the authors. This article is an open access article distributed under the terms and conditions of the Creative Commons Attribution (CC BY) license (https://creativecommons.org/licenses/by/4.0/).

\section{Introduction}

In the present decade, direct electron transfer (DET) has been considered between the redox proteins and electrode surface [1]. DET is significant in the construction of thirdgeneration biosensors between redox proteins or enzymes and original electrodes [2]. However, most redox proteins are difficult on electrodes because of the shielding of the redox active sites [3]. And also, it has been proved that nanomaterials with exclusive constructions be able to 
facilitate DET because of small size [4]. Carbon nanotubes (CNTs) have been attracted in electrochemistry because of their mechanical, structural properties, remarkable electrical and chemical features [5-7]. CNTs have been categorized in two major kinds based on the physical and schematically properties of carbon layers, in other words, the first one is single-wall carbon nanotubes (SWCNTs) and the second is multi-wall carbon nanotubes (MWCNTs) [8]. One type of MWCNTs is Bamboo which has a separate section layer between the walls. The first one (SWCNTs) can be able to prepared from one carbon layer and have a cylindrical graphene sheet. The second type (MWCNT) can be able to prepared by a different procedure that leads to formation of several carbon layers $[8,9]$.

Many researchers have been focused on these types of carbon-allotropes and showed that CNTs can be able to enhance and improve the electron-transfer responses of several types of enzymes. The preference of using SWCNTs, MWCNTs and Bamboo have not been completely studied in terms of electrochemical properties based on enzymatic activities. Recently, well-known scientists demonstrated the different responses as well as physicochemical properties of these carbon-based nanomaterials in the presence of glucose as a semi-optimized model of a biosensor and revealed that an array of single layer of carbons could lead to an acceptable linear range as well as improving the selectivity and sensitivity [1014]. From another perspective, another researcher group applied single and multi-walls carbonbased nanomaterials in constructing a xanthine-based nanobiosensor and again, the modified electrodes with multi-walls carbon-based nanomaterials showed significantly better results [15-17]. The immobilized polyphenol oxidase on SWCNTs can catalyze the oxidation of HCA [18]. Room temperature ionic liquids (RTIL) completely contained the ions at ambient temperature and also, it has concerned due to its unique chemical and physical properties [19]. However, the difference reason was not detected in modified SWCNTs, MWCNT and Bamboo like electrodes. In this study, three kinds of carbon nanotubes (Modified SWCNT, MWCNT and Bamboo-like CNTs) were investigated in electron transfer properties.

\section{Materials and Methods}

\subsection{Chemicals and reagents.}

Choline oxidase (ChOx) is extracted from Alcaligenes species $\left(11 \mathrm{U} / \mathrm{mg}^{-1}\right), 1$-Allyl-3methylimidazolium Chloride Room Temperature Ionic Liquid (RTIL), choline chloride (Sigma) SWCNTs, MWCNTs (Nanostructure\& Amorphous), Potassium phosphate $\left(\mathrm{K}_{2} \mathrm{HPO}_{4}\right.$ and $\mathrm{KH}_{2} \mathrm{PO}_{4}$ ) and $\mathrm{N}, \mathrm{N}$-dimethylformamide (DMF) (Merk) and BambooCNT (American Nanolab) were purchased. The properties of materials are listed: MWCNTs: $8 \mathrm{~nm}$ diameter, 0.5- $2 \mu \mathrm{m}$ length, $95 \%$ purity, $500 \mathrm{~m}^{2} / \mathrm{g}$ SSA, SWCNTs: $1-2 \mathrm{~nm}$ diameter, 5-30 $\mu \mathrm{m}$ length, $90 \%$ purity, $400 \mathrm{~m}^{2} / \mathrm{g}$ SSA and Bamboo: $30 \pm 10 \mathrm{~nm}$ diameter, $1-5 \mu \mathrm{m}$ length, $93 \%$ purity.

\subsection{Functionalization of CNTs.}

Functionalization of CNTs is described in several methods in the other papers, but here, we described a different method that briefly, $3 \mathrm{mg}$ of CNTs were dispersed in $5 \mathrm{ml}$ of $\mathrm{HNO}_{3}$ (35\% wt) (with $2 \mathrm{~h}$ sonication). Then, the final suspension was soaked with deionized water and filtered using a $0.45 \mu \mathrm{m}$ polytetrafluoroethylene filter (PTFE, Sartorius Biolab products Germany) and rinsed with deionized water until a neutral $\mathrm{pH}$ value was achieved. The filtered materials were dried under the IR lamp. 


\subsection{Characterization of the Functionalized of SWCNTs, MWCNTs and Bamboo like CNTs.}

The presence of functionalization of CNTs was identified on the treated SWCNTs, MWCNTs and Bamboo-like CNTs surfaces. The structures and chemical compositions of functionalized SWCNTs, MWCNTs and Bamboo-like CNTs were characterized by using Fourier Transform Infrared Spectroscopy (FTIR) (Thermo Nicolet Co., USA), Raman Spectroscopy and Scanning Electron Microscopy (SEM). For the preparation of samples, a PBS solution with a concentration of $0.2 \mathrm{M}$ and $\mathrm{pH} 7.0$ used. The electrochemical tests were done using a computerized Potentiostat/Galvanostat (Autolab Netherlands) along with a PowerSuite software package. All tests were done at $25^{\circ} \mathrm{C}$ in a specific electrochemical cell. These electrodes were applied containing saturated $\mathrm{Ag} / \mathrm{AgCl}$ (with the concentration of $3 \mathrm{M}$ $\mathrm{KCl}$ solution, Sigma-Aldrich) used as the reference electrode, hydrogen electrode [4] as reference to standard and a platinum wire electrode was applied as the working electrode (from Metrohm). FTIR spectrum shows that the oxidation of SWCNTs, MWCNTs and Bamboo-like CNTs on the surface wall and chemical composition of functionalized SWCNTs, MWCNTs and Bamboo-like CNTs was confirmed by FTIR in presence of carboxyl group. SEM image shows the existence of surface modification on the SWCNTs, MWCNTs and Bamboo-like CNTs structures. The method used in functionalization SWCNTs, MWCNTs and Bamboo-like CNTs have produced fragmented structure toward the functionalized SWCNTs, MWCNTs and Bamboo-like CNTs. Raman spectroscopy is used for the investigation of graphitic materials such as fullerenes, carbon nanotubes (CNTs), and graphite [20]. Raman spectroscopy is a spectroscopic method to detect vibrational, rotational, or low-frequency modes [21].

\subsection{Electrode modification.}

In the first step, The Glassy Carbon (GC) electrode was cautiously polished with different alumina slurries $(0.3$ and $10 \mu \mathrm{m})$. And then, Carboxyl functionalized CNTs $(1 \mathrm{mg})$ were floated in $0.5 \mathrm{ml}$ DMF (ultrasonic agitation) for the next tests. CNT-modified GC electrode was obtained through, briefly, carboxylated CNTs $(0.5 \mu \mathrm{L})$ with DMF was impregnated to the surface of electrode and dried at room temperature. The obtained electrodes were immersed in $\mathrm{BF}_{4}$ (solution) for $12 \mathrm{~h}$ at $4{ }^{\circ} \mathrm{C}$ in order to achieve ChOx/RTIL/CNTs/GC electrode. Finally, the obtained electrode floated in a stock solution of $\mathrm{ChOx}\left(6 \mathrm{~g} \mathrm{~L}^{-1}\right)$ for $12 \mathrm{~h}$ to proceed with enzyme immobilization.

\subsection{Voltammetry and Amperometry analysis.}

The direct electrochemistry of ChOx on RTIL/Bamboo-like CNTs, RTIL/MWCNTs and RTIL/SWCNTs nano-composite modified electrodes were studied by cyclic voltammetry (CV). Fixed nanocomposites containing CNTs, Ionic liquid and choline oxidase were used to evaluate the electrocatalytic activity of modified choline oxidase enzyme electrodes and its response was investigated by chronoamperometry to the addition of enzyme substrate choline chloride.

\section{Results and Discussion}

\subsection{Raman spectroscopy.}

Raman spectroscopy is a sensitive probe of the electronic structure. The first response of Raman spectra of CNTs is induced by disorder at around $1300 \mathrm{~cm}^{-1}$ for D mode. Covalent 
modification and defect concentration can be detected by this mode and $\mathrm{I}_{\mathrm{d}} / \mathrm{I}_{\mathrm{G}}$ ratio has been known as a defect concentration measurement. The $D$ to $G$ band intensity ratio is used for recognizing the level of functionalized CNTs. The measurement of intensity ratio (I (D)/I (G)) of $\mathrm{D}$ and $\mathrm{G}$ bands can provide simply by the number of defects. There is a direct connection between the increase of a number of sidewall defects and ID/IG ratio. There is a mode as a sensitive to the diameter of CNTs in which this diameter can be detected. Radial Breathing Mode (RBM) is a very sensitive parameter to the diameter of CNTs and also, this diameter distribution of CNTs can be detected [22]. In this study, this method was used to characterize the functional groups on the surface of SWCNTs, MWCNTs and Bamboo-like CNTs (Fig. 1 $\mathrm{A}$ and B). There were detected four absorption peaks at around 258 and $1324,1554,2632, \mathrm{~cm}^{-1}$ in the Raman spectrum of SWCNTs, three absorption peaks at around $276,1323,1550, \mathrm{~cm}^{-1}$ in the Raman spectrum of MWCNTs and three absorption peaks at around 255,1321,1545, in the Raman spectrum of Bamboo CNTs.

Table 1 compares the parameters of Raman spectroscopy. It shows that the ratio $I_{d} / I_{G}$ in Bamboo-like CNTs before and after acid treated was 1.3, 1.14, respectively. The ratio $\mathrm{I}_{\mathrm{d}} / \mathrm{I}_{\mathrm{G}}$ of MW CNTs was 0.87, 1.12 and SW CNTs was 0.13, 0.16, respectively. This ratio was reduced in the Bamboo-like CNTs sample but was increased in other samples (MW and SW CNTs). The intensity of D band (1.34) was reduced in Bamboo-like CNTs after acid treated and also, the frequency of D band was led to a negative shift in Bamboo-like CNTs cm${ }^{-1}$. The intensity of D band was reduced in MW and SW after acid treated (10.9 and 12.7, respectively). The Intensity of the G band was reduced in Bamboo, MW and SW CNTs after acid treated (5.64, 1.98 and 16.08, respectively). The intensity of RBM was reduced in Bamboo, MW and SW CNTs after acid treated (108.75, 12.6 and 16.07, respectively). The frequency of RBM band was negatively shifted for Bamboo and SW CNTs after acid treated, $\left(22 \mathrm{~cm}^{-1}\right.$ and $18 \mathrm{~cm}^{-}$ 1 , respectively), but was positively shifted for MW CNTs $\left(4 \mathrm{~cm}^{-1}\right)$. Therefore, it can be concluded that the Bamboo-like CNTs had better results. Lower frequencies of electron transfer of $\mathrm{G}$ band shifts showed the functionalized nanotubes. These shifts were detected in all samples. The following table indicates changes in CNTs before and after acid treatment.
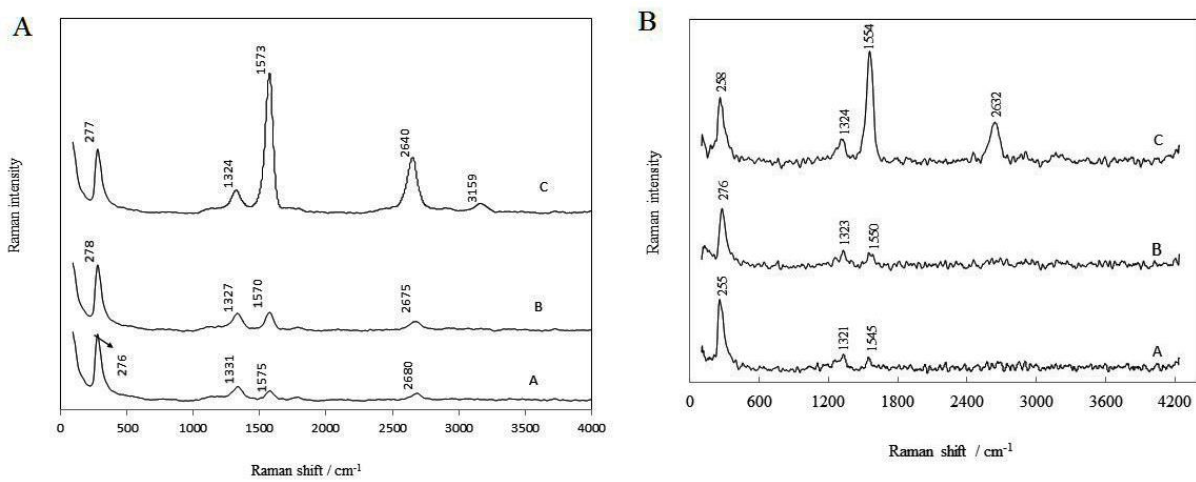

Figure 1. A: Raman spectrum from different carbon nanotubes (A) Bamboo-like CNTs, (B) multiwall CNTs, (C) single-wall CNTs before acid treated. B: Raman spectrum from different carbon nanotubes (A) Bamboo-like CNTs, (B) Multiwall CNTs, (C) single-wall CNTs after acid treated.

\subsection{FTIR spectroscopy.}

FTIR spectroscopy is used for studying the secondary construction of proteins. FTIR was performed in the range 400 to $4000 / \mathrm{cm}^{-1}$ for the detection of the practical group attached on CNTs. The peaks show the bands as follows: $1613-1731 \mathrm{~cm}^{-1}, 2800-3000 \mathrm{~cm}^{-1}, 1000-1185$ 
$\mathrm{cm}^{-1}$ and 3400 to $2400 \mathrm{~cm}^{-1}$ corresponds to Carbonyl $(\mathrm{C}=\mathrm{O}), \mathrm{C}-\mathrm{H}$ asymmetric, $\mathrm{C}-\mathrm{O}-\mathrm{C}$ and $\mathrm{OH}$, respectively [23]. Fig. 2 shows the FTIR spectra of SWCNTs, MWCNTs and Bamboolike CNTs after acid treated. The diagram of the SWCNTs showed a peak at 1722-3010-1566 and $1020 \mathrm{~cm}^{-1}$. And also, the MWCNTs diagram showed peaks at 3370-2910-1700-1563 and $1143 \mathrm{~cm}^{-1}$. Bamboo-like CNTs diagram showed peaks at 3410-2919-1063-1400 and $1078 \mathrm{~cm}^{-1}$. The IR spectra of the Bamboo-like CNTs, MWCNTs and SWCNTs suggested at 3410, 3370 and $3010 \mathrm{~cm}^{-1}$ in the presence of carboxyl and carboxylate groups, respectively. The functionalization of CNTs was confirmed according to the above results.

\subsection{Morphology analysis.}

SEM images were used to characterize and compare the morphologies of the Bamboolike CNTs, MWCNTs, SWCNTs, Bamboo-like CNTs/RTIL, MWCNTs/RTIL, SWCNTs/RTIL, Bamboo-like CNTs/RTIL/ChOx, MWCNTs/RTIL/ChOx and SWCNTs/RTIL/ChOx. The initial Multi-walled CNTs had a short length and also, CNTs length was shorter in the process of functionalization. The image of Multi-walled nanotubes appears spherical. Fig. 3A, B and C show the FE-SEM images of the electrode after deposition of Bamboo-like CNTs, MWCNTs and SWCNTs, respectively. Fig. 3D, E and F show surface morphology investigation results of the modified CNTs electrodes after deposition of RTIL on Bamboo-like CNTs, MWCNTs and SWCNTs, respectively. Fig. 3G, H and K show FE-SEM images of the RTIL/Bamboo-like CNTs /GC, RTIL/ MWCNTs /GC and RTIL/SWCNTs /GC electrodes after adsorption of $\mathrm{ChOx}$, respectively.

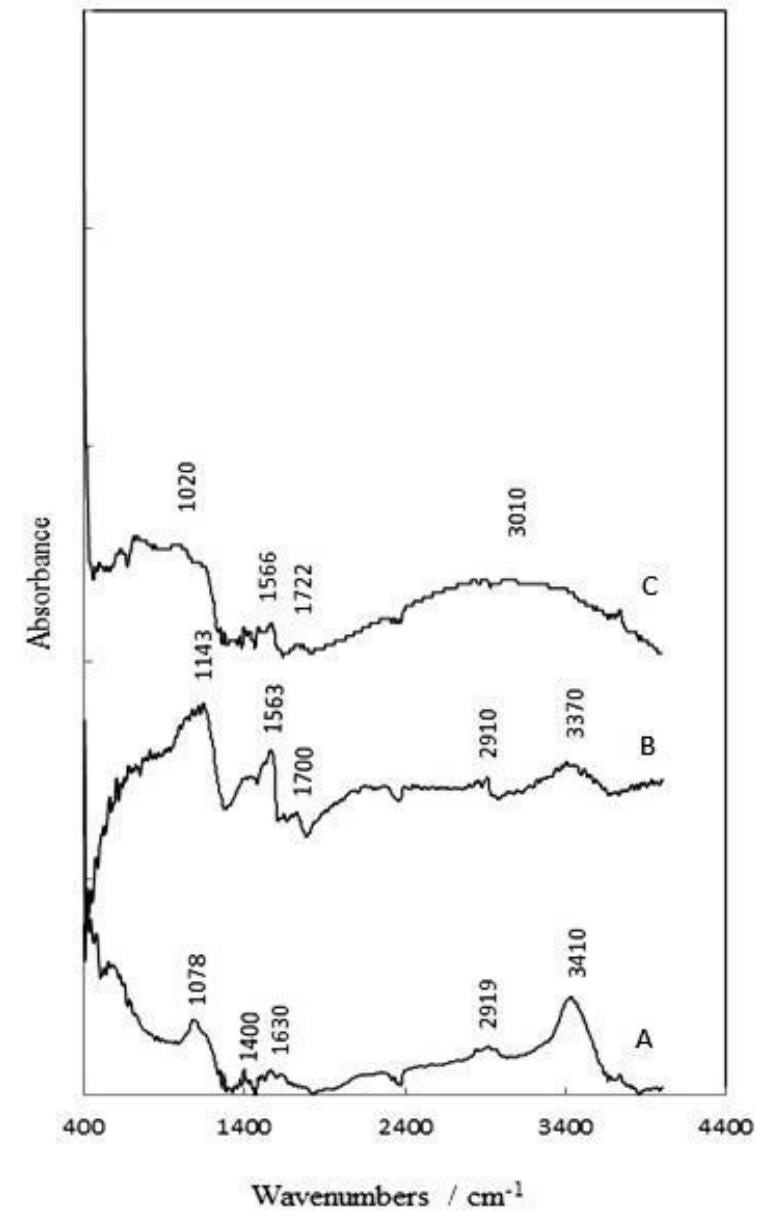

Figure 2. FTIR spectra of (A) Bamboo-like CNTs, (B) multi-wall CNTs and (C) single-wall CNTs after acid treated. 
A

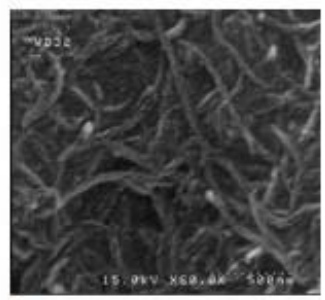

D

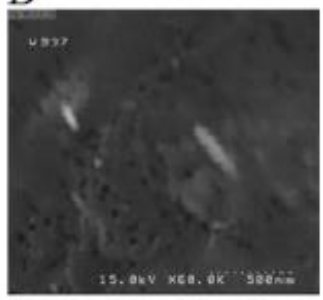

G

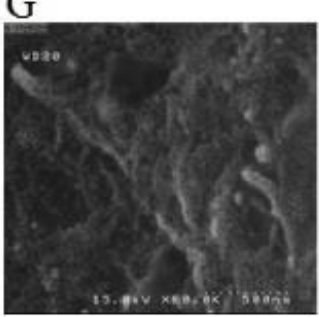

B

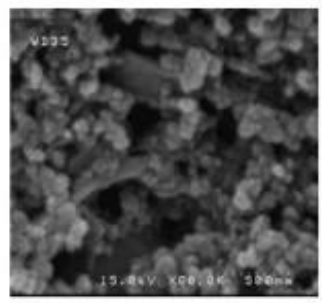

$\mathrm{E}$

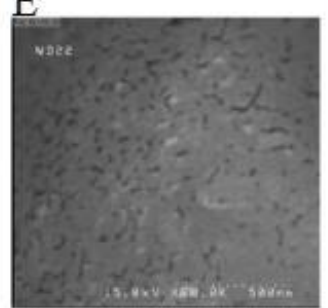

$\mathrm{H}$

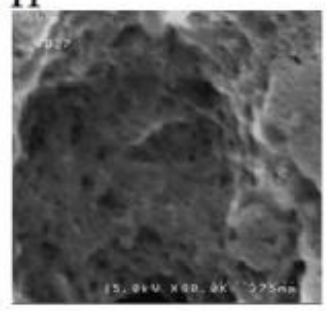

$\mathrm{C}$

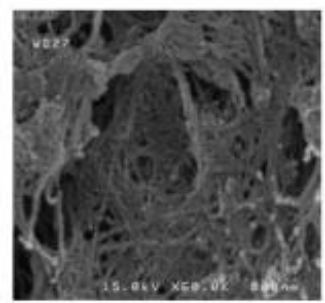

$\mathrm{F}$

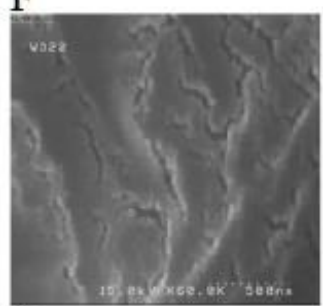

$\mathrm{K}$

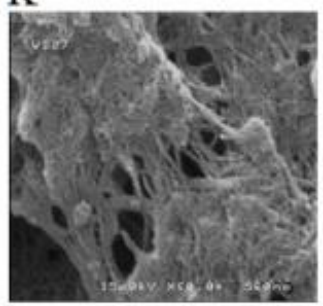

Figure 3. SEM image of (A) Bamboo like CNTs , (B) multi-wall CNTs and (C) single-wall CNTs after acid treated, (D) Bamboo like CNTs/ RTIL , (E) multi-wall CNTs/ RTIL and (F) single-wall CNTs/ RTIL , (G) Bamboo like CNTs/ RTIL/ ChOx , (H) multi-wall CNTs/ RTIL/ChOx and (K) single-wall CNTs/ RTIL/ChOx.

\subsection{Electrochemical characterization.}

In this section, ChOx showed no response on the bare GC electrode (Fig. 4 A, B and C). And also, the GC electrode was modified with RTIL/Bamboo-like CNTs, RTIL/MWCNTs and SWCNTs, respectively. Modified electrodes have exhibited no peaks due to there were no electro activists. But, ChOx was immobilized on RTIL/Bamboo-like CNTs, RTIL/MWCNT and SWCNTs and also, a pair of well-defined redox peaks were observed in three modified electrodes. The advantage in ChOx loading at HOOCCNTs can be accredited to the fact that the communication between enzyme and RTIL/CNTs nanocomposite is generally administered by hydrogen bonding [24]. The carbon nanotube surface morphology of modified electrode and cyclic voltammogram of enzyme was found in the around of the electrode in order to show that the stabilization of the enzyme on the electrode surface or around of the electrode in nitrogen-saturated phosphate buffer ( $\mathrm{pH}: 7)$ condition in different scan rates. The potential rate of a dependent enzyme of anodic and cathodic is shown in Fig. 5 and 6 A, B and C.

A

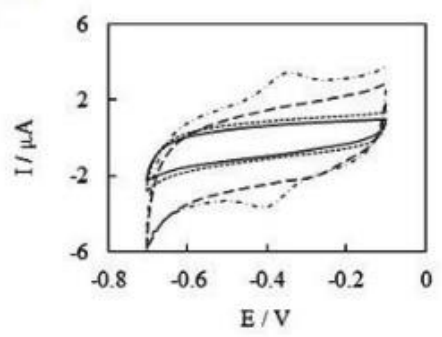

B

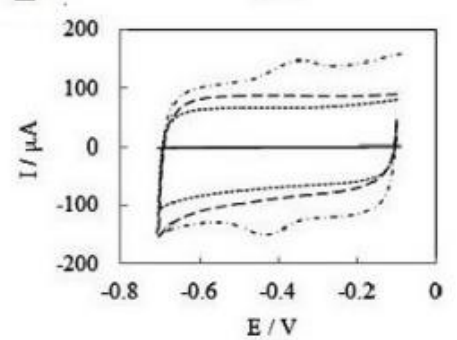

$\mathrm{C}$

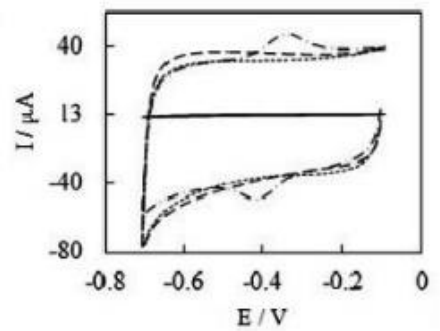

Figure 4. Cyclic Voltammograms of Bamboo-like CNTs/RTIL/ChOx/GC (A), Multi-wall CNTs/RTIL/ChOx/ GC (B) and single wall CNT/RTIL/ChOx/GCE (C) in $0.2 \mathrm{M} \mathrm{PBS} \mathrm{(pH} \mathrm{7.0)} \mathrm{at} \mathrm{a} \mathrm{scan} \mathrm{rate} \mathrm{of} 100 \mathrm{mV} / \mathrm{s}$. 
A

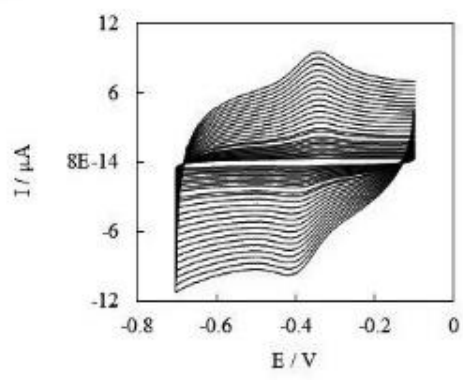

B

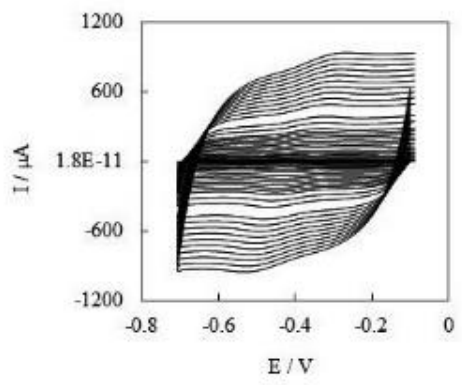

$\mathrm{C}$

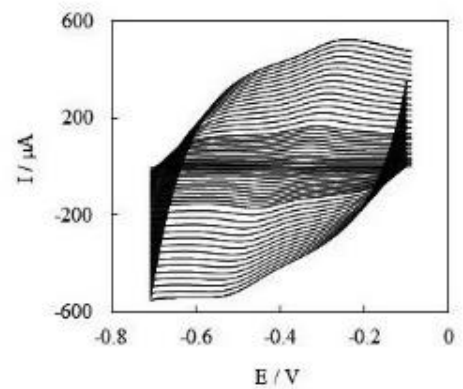

Figure 5. Cyclic Voltammograms of Bamboo-like CNTs/RTIL/ChOx/GC (A), multi-wall $\mathrm{CNTs} / \mathrm{RTIL} / \mathrm{ChOx} / \mathrm{GC}(\mathrm{B})$ and single-wall CNTs/RTIL/ChOx/GC (C) in $0.2 \mathrm{M}$ PBS (pH 7.0) with scan rates of $10-1000 \mathrm{mV} / \mathrm{s}$.

A

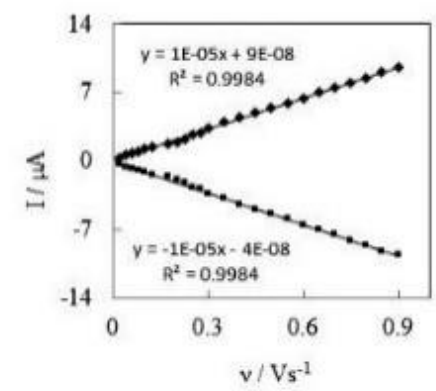

B

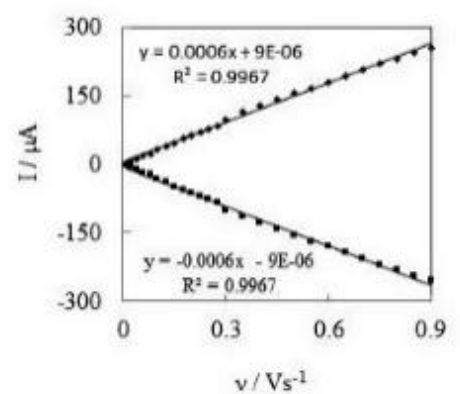

$\mathrm{C}$

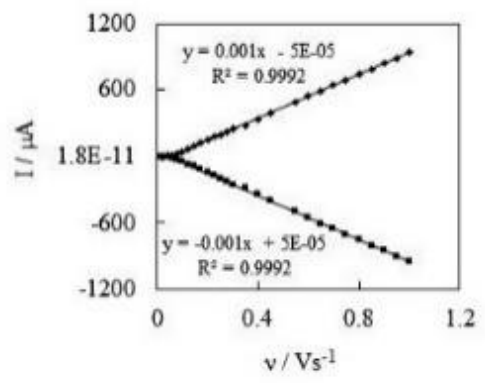

Figure 6. Dependent enzyme of anodic and cathodic peake of the stabilized enzyme to scan the modified electrode with Bamboo-like CNTs/ RTIL/ChOx/GC (A), multi-wall CNTs/RTIL/ChOx/GC (B) and single-wall CNTs/RTIL/ChOx/GC (C).

\subsection{Amperometric response.}

Fig. 7 and 8 (A, B and C) show the biocatalytic activities of ChOx/RTIL/CNTs/GC electrodes by amperometry. It can result in the biocatalytic activity of the enzyme was various base on the functional groups of CNTs. A double role for RTIL/CNTs nanocomposites: CNTs performance as a promoter for protein electron transfer at the electrode surface, while RTIL acts as a biocompatible matrix by which the natural construction of ChOx could be conserved [25].

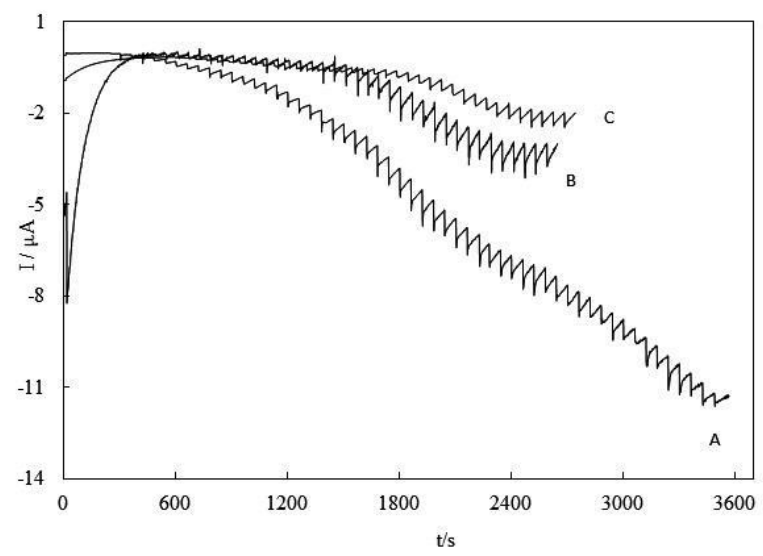

Figure 7. Amperometry response of modified electrode with Bamboo-like CNTs/ RTIL/ChOx/GC (A), multiwall CNTs/RTIL/ChOx/GC (B) and single-wall CNTs/RTIL/ChOx/GC (C). The electron rotation speed was $500 \mathrm{rpm}$ for each case. 
Table 2 shows that the electroanalytical parameters of ChOx/RTIL/Bamboo-like CNTs/GC, ChOx/RTIL/MWCNTs/GC and ChOx/RTIL/SWCNTs/GC for choline detection. It can result from this table, the detection limit was better in ChOx/RTIL/Bamboo-like CNTs/GC than ChOx/RTIL/ MWCNTs/GC and ChOx/RTIL/SWCNTs /GC. The linear range of ChOx/RTIL/Bamboo-like CNTs/GC was extended than ChOx/RTIL/ MWCNTs /GC and ChOx/RTIL/SWCNTs /GC. And also, the sensitivity of ChOx/RTIL/Bamboo-like CNTs/GC was more two and five times of ChOx/RTIL/ MWCNTs /GC and ChOx/RTIL/SWCNTs /GC, respectively. ChOx/RTIL/Bamboo-like CNTs/GC modified electrode had a better result than other modified electrode with MW and SW base on the aforementioned parameters.

A

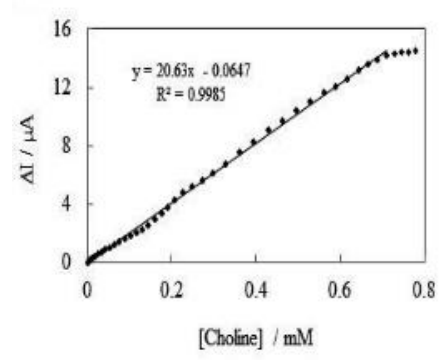

B

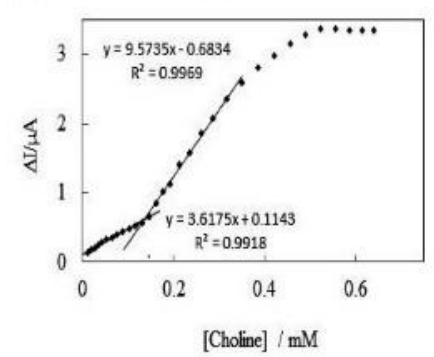

$\mathrm{C}$

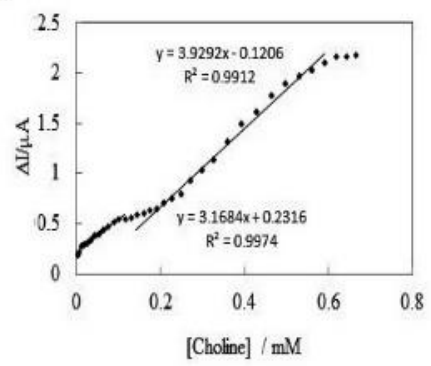

Figure 8. Calibration curve for the detection of modified Cholin enzyme electrode with Bamboo-like CNTs/RTIL/ChOx/GC (A), multi-wall CNTs/RTIL/ChOx/GC (B) and single-wall CNTs/RTIL/ChOx/GC (C).

Table 1. comparison of Raman spectrum parameters such as $\mathrm{Id} / \mathrm{Ig}$, Intensity of D band, the frequency of D band, Intensity of $\mathrm{G}$ band, Frequency of $\mathrm{G}$ band, Frequency of RBMand Intensity of RBM in different CNTs

\begin{tabular}{|c|c|c|c|c|c|c|c|c|c|c|c|c|c|c|}
\hline & \multicolumn{2}{|c|}{ Id/Ig } & \multicolumn{2}{|c|}{$\begin{array}{c}\text { The } \\
\text { intensity of } \\
\text { D band }\end{array}$} & \multicolumn{2}{|c|}{$\begin{array}{l}\text { Frequency } \\
\text { Of D band }\end{array}$} & \multicolumn{2}{|c|}{$\begin{array}{l}\text { The intensity } \\
\text { of } G \text { band }\end{array}$} & \multicolumn{2}{|c|}{$\begin{array}{l}\text { Frequency } \\
\text { Of G band }\end{array}$} & \multicolumn{2}{|c|}{$\begin{array}{c}\text { Frequency } \\
\text { Of RBM }\end{array}$} & \multicolumn{2}{|c|}{$\begin{array}{c}\text { Intensity of } \\
\text { RBM }\end{array}$} \\
\hline $\begin{array}{l}\text { CNTs } \\
\text { type }\end{array}$ & $\mathrm{C}^{*}$ & $* \mathrm{~F}$ & $\mathbf{C}^{*}$ & $* \mathrm{~F}$ & $\mathbf{C}^{*}$ & $* \mathrm{~F}$ & $\mathbf{C}^{*}$ & $* \mathrm{~F}$ & $\mathbf{C}^{*}$ & $* \mathrm{~F}$ & $\mathbf{C}^{*}$ & $* \mathrm{~F}$ & $\mathbf{C}^{*}$ & $* \mathrm{~F}$ \\
\hline \multirow[b]{2}{*}{ Bamboo } & $1 / 3$ & $1 / 14$ & 248 & 184 & 1334 & 1331 & 275 & $48 / 7$ & 1578 & 1545 & 279 & 257 & 1740 & 16 \\
\hline & \multicolumn{2}{|c|}{$\begin{array}{c}0.16 \\
\text { Reduce }\end{array}$} & \multicolumn{2}{|c|}{$\begin{array}{c}1.34 \\
\text { Reduce }\end{array}$} & \multicolumn{2}{|c|}{$\begin{array}{l}3 \mathrm{~cm}^{-1} \\
\text { Shift }\end{array}$} & \multicolumn{2}{|c|}{$\begin{array}{c}5.64 \\
\text { Reduce }\end{array}$} & \multicolumn{2}{|c|}{$\begin{array}{c}33 \mathrm{~cm}^{-1} \\
\text { Shift }\end{array}$} & \multicolumn{2}{|c|}{$\begin{array}{c}22 \mathrm{~cm}^{-1} \\
\text { Shift }\end{array}$} & \multicolumn{2}{|c|}{$\begin{array}{l}108.75 \\
\text { Reduce }\end{array}$} \\
\hline \multirow[b]{2}{*}{ MW } & 0.87 & 1.12 & 360 & 32.9 & 1331 & 1327 & 377 & 190 & 1575 & 1550 & 275 & 279 & 1710 & 135.16 \\
\hline & \multicolumn{2}{|c|}{0.25 Increase } & \multicolumn{2}{|c|}{$\begin{array}{c}10.9 \\
\text { Reduce }\end{array}$} & \multicolumn{2}{|c|}{$\begin{array}{c}4 \mathrm{~cm}^{-1} \\
\text { Shift }\end{array}$} & \multicolumn{2}{|c|}{$\begin{array}{c}1.98 \\
\text { Reduce }\end{array}$} & \multicolumn{2}{|c|}{$\begin{array}{c}25 \mathrm{~cm}^{-1} \\
\text { Shift }\end{array}$} & \multicolumn{2}{|c|}{$\begin{array}{c}4 \mathrm{~cm}^{-1} \\
\text { Shift }\end{array}$} & \multicolumn{2}{|c|}{$\begin{array}{c}12.6 \\
\text { Reduce }\end{array}$} \\
\hline \multirow[b]{2}{*}{ SW } & 0.13 & 0.16 & 445 & $\begin{array}{c}34.9 \\
7\end{array}$ & 1324 & 1324 & 3380 & 210.12 & 1573 & 1556 & 279 & 261 & 2410 & 149.95 \\
\hline & \multicolumn{2}{|c|}{$\begin{array}{c}0.03 \\
\text { Increase }\end{array}$} & \multicolumn{2}{|c|}{$\begin{array}{c}12.7 \\
\text { Reduce }\end{array}$} & \multicolumn{2}{|c|}{ Without shift } & \multicolumn{2}{|c|}{$\begin{array}{c}16.08 \\
\text { Reduce }\end{array}$} & \multicolumn{2}{|c|}{$\begin{array}{l}17 \mathrm{~cm}^{-1} \\
\text { Shift }\end{array}$} & \multicolumn{2}{|c|}{$\begin{array}{l}18 \mathrm{~cm}^{-1} \\
\text { Shift }\end{array}$} & \multicolumn{2}{|c|}{$\begin{array}{l}16.07 \\
\text { Reduce }\end{array}$} \\
\hline
\end{tabular}

*C: Crude, *F: Functionalized

Table 2. Analytical comparison of three different sensing parameters designed and comparison of kinetic

\begin{tabular}{|c|c|c|c|c|c|c|c|}
\hline & $\begin{array}{l}\text { LOD } \\
(\mu \mathrm{M})\end{array}$ & $\begin{array}{c}\text { Linear } \\
\text { range } \mathrm{mM}\end{array}$ & $\begin{array}{c}\text { Sensitivity } \\
\left(\mu \mathrm{A} / \mathrm{mM}^{2} \mathrm{~cm}^{2}\right)\end{array}$ & $\mathrm{E}(\mathrm{mV})$ & $\Delta \mathrm{Ep}(\mathrm{mV})$ & $\begin{array}{c}\mathrm{K}_{\mathrm{s}}\left(\mathrm{s}^{-}\right. \\
1)\end{array}$ & $\left(\mathrm{mol} / \mathrm{cm}^{2}\right) \Gamma$ \\
\hline ChOx/RTIL/BCNTs/GC & 0.28 & $\begin{array}{l}1.2 \times 10^{-3}- \\
7.0 \times 10^{-1}\end{array}$ & 294 & -347 & 56 & 23.11 & $3.3^{*} 10^{-7}$ \\
\hline ChOx/RTIL/MWCNTs/GC & 3.08 & $\begin{array}{l}1.2 \times 10^{-2}- \\
2.8 \times 10^{-1}\end{array}$ & 136.76 & -397 & 72 & 1.75 & $2.16^{*} 10^{-6}$ \\
\hline ChOx/RTIL/SWCNTs/GC & 1.97 & $\begin{array}{l}1.9 \times 10^{-1}- \\
5.9 \times 10^{-1}\end{array}$ & 56.13 & -379 & 83 & 1.49 & $1.5^{*} 10^{-6}$ \\
\hline
\end{tabular}

\section{Conclusions}

In the present study, the use of three kinds of carbon nanotubes was made by creating electrical communication between the redox center of the enzyme choline oxidase and the electrode surface. All three types of modified CNTs were known as well-inductor for electron transfer but, ChOx/RTIL/Bamboo-like CNTs/GC showed a better limit of detection, sensitivity 
and linear range than other modified CNTs (ChOx/RTIL/ MWCNTs /GC and ChOx/RTIL/SWCNTs /GC). The enzyme was uniformly stabilized on Bamboo-like CNTs. Therefore, Bamboo-like CNTs was an appropriate CNTs for design diagnostic sensor choline in comparison to other modified CNTs.

\section{Funding}

This research received no external funding.

\section{Acknowledgments}

The authors would like to Baqiyatallah University of Medical Sciences, Tehran, Iran for their kind help.

\section{Conflicts of Interest}

The authors declare no conflict of interest.

\section{References}

1. Chaplin, M.F.; Bucke, C. Enzyme technology. CUP Archive. 1990.

2. Hildebrand, D.P.; Tang, H.L.; Luo, Y.; Hunter, C.L.; Smith, M.; Brayer, G.D.; Mauk, A.G. Efficient coupled oxidation of heme by an active site variant of horse heart myoglobin. JACS 1996, 118, 12909-12915, https://doi.org/10.1021/ja9620043.

3. Ma, G.X.; Wang, Y.G.; Wang, C.X.; Lu, T.H.; Xia, Y.Y. Hemoglobin immobilized on whisker-like carbon composites and its direct electrochemistry. Electrochim. Acta 2008, 53, 4748-4753, https://doi.org/10.1016/j.electacta.2008.01.092.

4. Yang, M.; Qu, F.; Li, Y.; He, Y.; Shen, G.; Yu, R. Direct electrochemistry of hemoglobin in gold nanowire array. Biosens Bioelectron 2007, 23, 414-20, https://doi.org/10.1016/j.bios.2007.05.003.

5. Baughman, R.H.; Zakhidov, A.A.; De Heer, W.A. Carbon nanotubes--the route toward applications. Science 2002, 297, 787-792, https://doi.org/10.1126/science.1060928.

6. Vashist, A.; Kaushik, A.; Vashist, A.; Sagar, V.; Ghosal, A.; Gupta, Y.K.; Ahmad, S.; Nair, M. Advances in carbon nanotubes-hydrogel hybrids in nanomedicine for therapeutics. Adv Healthc Mater 2018, 7, https://doi.org/10.1002/adhm.201701213.

7. Schroeder, V.; Savagatrup, S.; He, M.; Lin, S.; Swager, T.M. Carbon Nanotube Chemical Sensors. Chem Rev 2019, 119, 599-663, https://doi.org/10.1021/acs.chemrev.8b00340.

8. Iijima, S. Helical microtubules of graphitic carbon. Nature (London) 1991, 354, 56-58, https://doi.org/10.1038/354056a0.

9. Zhou, Y.; Fang, Y.; Ramasamy, R.P. Non-Covalent Functionalization of Carbon Nanotubes for Electrochemical Biosensor Development. Sensors (Basel) 2019, 19, 392, https://doi.org/10.3390/s19020392.

10. Yao, Y.; Shiu, K.K. Electron-transfer properties of different carbon nanotube materials, and their use in glucose biosensors. Anal. Bioanal. Chem 2007, 387, 303-309, https://doi.org/10.1007/s00216-006-0924-1.

11. Daneshparvar, H.; Sadat-Shirazi, M.S.; Fekri, M.; Khalifeh, S.; Ziaie, A.; Esfahanizadeh, N.; Vousooghi, N.; Zarrindast, M.-R. NMDA receptor subunits change in the prefrontal cortex of pure-opioid and multidrug abusers: a post-mortem study. Eur Arch Psychiatry Clin Neurosci 2019, 269, 309-315, https://doi.org/10.1007/s00406-018-0900-8.

12. Esfahanizadeh, N.; Daneshparvar, P.; Takzaree, N.; Rezvan, M.; Daneshparvar, N. Histologic Evaluation of the Bone Regeneration Capacities of Bio-Oss and MinerOss X in Rabbit Calvarial Defects. Int J Periodontics Restorative Dent 2019, 39, e219-e227, https://doi.org/10.11607/prd.4181.

13. Esfahanizadeh, N.; Yousefi, H. Successful implant placement in a case of florid cemento-osseous dysplasia: a case report and literature review. J Oral Implantol 2018, 44, 275-279, https://doi.org/10.1563/aaid-joi-D17-00140.

14. Niri, A.D.; Faridi-Majidi, R.; Saber, R.; Khosravani, M.; Adabi, M. Electrospun carbon nanofiber-based electrochemical biosensor for the detection of hepatitis B virus. Biointerface Res. Appl 2019, 9, 4022-4026, https://doi.org/10.33263/briac94.022026.

15. Anik, Ü.; Cubukcu, M. Examination of the electroanalytic performance of carbon nanotube (CNT) modified carbon paste electrodes as xanthine biosensor transducers. Turk J Chem 2008, 32, 711-719. 
16. Mathiyalagan, S.; Mandal, B.K. Preparation of metal doped quercetin nanoparticles, characterization and their stability study. Lett. Appl. NanoBioScience 2019, 8, $704 \quad-710$, https://doi.org/10.33263/LIANBS84.704710.

17. Davis, T.A.; Patberg, S.M.; Sargent, L.M.; Stefaniak, A.B.; Holland, L.A. Capillary electrophoresis analysis of affinity to assess carboxylation of multi-walled carbon nanotubes. Anal Chim Acta 2018, 1027, 149-157, https://doi.org/10.1016/j.aca.2018.03.034.

18. Mohammadi, A.; Moghaddam, A.B.M.; Dinarvand, R.; Rezaei-Zarchi, S. Direct Electron Transfer of Polyphenol Oxidase on Carbon Nanotube Surfaces: Application in Biosensing. Int. J. Electrochem. Sci 2009, 4, 895-905.

19. Wei, D.; Ivaska, A. Applications of ionic liquids in electrochemical sensors. Anal. Chim. Acta 2009, 607, 126-135, https://doi.org/10.1016/j.aca.2007.12.011.

20. Shin K; Lee CO; Kim E; JY, K. Surface probe of single-walled carbon nanotubes irradiated by high-energy proton beams. J. Korean Phys. Soc 2007, 51, 1488-1491 https://doi.org/10.3938/jkps.51.1488.

21. Gardiner, D.J. Introduction to Raman Scattering, In: Practical Raman Spectroscopy. Gardiner, D.J.; Graves, P.R. Editors. Springer Berlin Heidelberg, Berlin, Heidelberg, 1989; pp. 1-12, https://doi.org/10.1007/978-3642-74040-4.

22. Murphy, H.; Papakonstantinou, P.; Okpalugo, T.I.T. Raman study of multiwalled carbon nanotubes functionalized with oxygen groups. $J$ VAC SCI Technol B 2006, 24, 715-720, https://doi.org/10.1116/1.2180257.

23. Khare, B.N.; Meyyappan, M.; Cassell, A.M.; Nguyen, C.V.; Han, J. Functionalization of Carbon Nanotubes Using Atomic Hydrogen from a Glow Discharge. Nano Lett 2002, 2, 73-77, https://doi.org/10.1021/nl015646j.

24. Rahimi, P.; Ghourchian, H.; Sajjadi, S. Effect of hydrophilicity of room temperature ionic liquids on the electrochemical and electrocatalytic behaviour of choline oxidase. Analyst 2012, 137, 471-475, https://doi.org/10.1039/C1AN15732A.

25. Sajjadi, S.; Ghourchian, H.; Rafiee-Pour, H.A.; Rahimi, P. Accelerating the electron transfer of choline oxidase using ionic-liquid/NH2-MWCNTs nano-composite. J. Iran. Chem. Soc 2012, 9, 111-119, https://doi.org/10.1007/s13738-011-0044-5. 